\title{
A Comparative Assessment of Embedded Energy Storage and Electric Vehicle Integration in a Community Virtual Power Plant
}

\author{
Oghenovo Okpako ${ }^{1}$, Haile-Selassie Rajamani ${ }^{2}$, Prashant Pillai ${ }^{3}$, Ugonna Anuebunwa ${ }^{1}$, and K. Shanti \\ Swarup $^{4}$ \\ ${ }^{1}$ Faculty of Engineering and Informatics, \\ University of Bradford, UK \\ \{ookpako, U.R.Anuebunwa\}@bradford.ac.uk \\ 2 Faculty of Engineering \& Information Sciences, \\ University of Wollongong, Dubai, UAE \\ HaileRajamani@uowdubai.ac.ae \\ 3 Faculty of Technology, Design and Environment, \\ Oxford Brookes University, UK \\ ppillai@brookes.ac.uk \\ 4 Electrical Engineering Department, \\ Indian Institute of Technology, Madras, India \\ swarup@ee.iitm.ac.in
}

\begin{abstract}
Among the key objectives of the smart grid technology are to foster the grid integration of renewable energy as well as market participation of domestic energy consumers through demand response program. Energy storage remains a key component of the smart grid. Past works on integration of energy storage at the domestic side of the electricity grid has identified the electric vehicle technology (EV) and the embedded energy storage (EES) technology, etc. However, it was difficult to compare between these technologies in terms of business incentives and technical performance. This was investigated in this work, and the results are presented. It was propose to use percentage difference to compare between VPP with EES and VPP with EV. The results shows that the difference in prosumers incentives between VPP with EES and VPP with EV is very low. It is approximately $0.89 \%$. However, the percentage difference in VPP operator profit between VPP with EES and VPP with EV is very high. It is approximately $85.3 \%$. The VPP makes very high profit in the VPP EES case compared to VPP EV case. The same also applies to the VPP cumulative performance where the percentage difference in the VPP cumulative performance between VPP with EES and VPP with EV is approximately $10.9 \%$. This has implication on the storage mechanism to be integrated in to a VPP at the domestic level as well the business model to be adopted.
\end{abstract}

Keywords: Prosumer; Battery; Virtual Power Plant (VPP); Genetic Algorithm (GA); Smart Grid, State of charge.

\section{Introduction}

Sustainable energy production and the efficient utilization of available energy resources remains one of our greatest challenge towards minimizing carbon emission from fossil fuel. In the UK, the government is keen to reduce its carbon footprint by $80 \%$ by the year 2050 .

Energy storage is a key option in tackling the global challenge of climate change, as it can help in increasing the use of clean energy from intermittent renewable energy sources. Grid integration of energy storage would help in improvement of power quality; provision of peak shaving and valley filling services; deferral of investment on grid's enhancement; demand side management; spinning reserve; black start services; and provision of load following services, etc.[1], [2], [3], [4], [5], [6], [7].

The ongoing global restructuring of electric power utilities is expected to create a competitive market. The consumer role is envisage to change to that of a prosumer who both consume and produce energy. Energy storage becomes an asset to the prosumer, which can be use for selling demand response in the power market. The use of energy storage at the domestic (prosumer) side of the electricity grid can be in form of embedded energy storage (EES), and electric vehicle (EV). In EES, the storage is place in the house of the prosumer and is stationary. In EV, the storage is inside the vehicle and can only be connected to the grid when the vehicle is idle. EV can be classify as a mobile storage. The use of EV for participation in the power market and for providing grid support is known as vehicle to grid (V2G). Kempton proposed this concept [8], [9], [10]. 
Due to the small power capacity of EES and EV, prosumers cannot participate directly in the power market, as this is done at the wholesale level. Prosumers would require the service of a third party called the Virtual Power plant (VPP). The VPP is an aggregator and a third party agent that combine large number of units of prosumers EVs, EESs and other energy resource device for participation in the wholesale power market. Participation of the VPP in the power markets, involves the VPP establishing contract with EV's and EES's owners to allow them use their storage device for energy/market transaction while providing support to the grid support. A prosumer who allows the VPP to use their storage for market participation gets a financial compensation.

The business potentials of EES as part of a VPP have been researched by these authors: [11], [12], [13]. In [11], EES can maximize prosumers feed-in tariff reward. Also, multiple power service provision by EES can increase the financial value of EES under a time of use tariff as well as a dynamic use of system pricing [11]. According to [12], [13] on EES, it is possible to have a pricing regime that simultaneously incentivize both the VPP operator and the prosumer while meeting the VPP objectives. In addition, the business potentials of EVs in the power market have been investigated by these authors [10], [14], [15]. According to [10], EV owners would get more financial incentives when there is capacity payment for provision of ancillary service.

Intelligent control strategies has been proposed as way to deal with large scale integration of energy storage in to the grid [16], [17]. This is to prevent increase in load at transmission, sub transmission and distribution level [18], need for an additional investment in grid infrastructure as a result of prosumers discretion for fast charging and charging time, as well as the coincidence between peak load of EV and non-EV on grid's reliability [19].

While existing literatures on grid integration of EES and EV has explored its business potential and its energy management strategy. There is no work known by this author, which has compared between the EES and EV in terms of technical performance for provision of dynamic load levelling and the business case. There is no clarity on whether EES offers a better business incentives and technical performance compared to EV vis-à-vis. This was investigated in this work.

This paper is organized as follows; section 2 is a description of the model, section 3 is the mathematical modelling, section 4 is the genetic algorithm optimization implementation, section 5 is the developed cumulative performance index for measuring VPP technical performance, section 6 is the simulation parameters, section 7 is the results and discussion, and section 8 is the conclusion.

\section{Framework of Virtual Power Plant Model}

In this work, the VPP model was considered under two scenarios of storage integration. These includes: EES and $\mathrm{EV}$.

\subsection{Embedded Energy Storage Scenario}

In EES, each of the prosumers where assumed to have battery storage embedded inside their house. The batteries are aggregated in to the VPP, and are use for participation in the power market at the wholesale level. Fig. 1, is the diagram showing the VPP model under EES scenario.

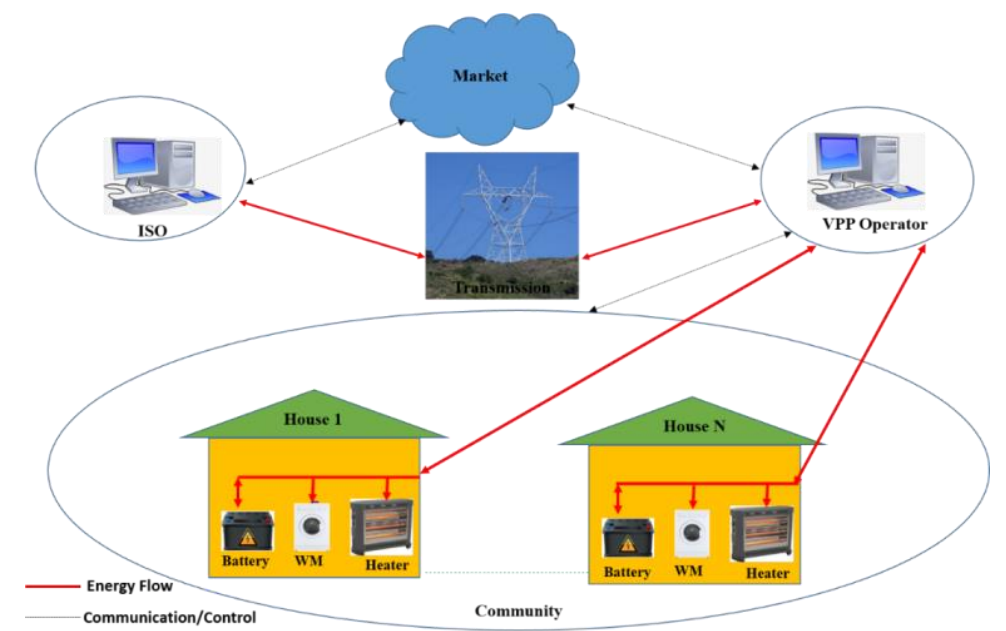

Fig. 1. Architecture of the Virtual Power Plant model (using EES). 
In Fig. 1, $\mathrm{N}$ is the total number of houses within the community aggregated in to the VPP. Each house is own by a prosumer. Each prosumer sells energy to the VPP operator through discharging of their battery. In this work a community consisting of three prosumers is investigated $(\mathrm{N}=3)$. Each prosumer buy energy from the VPP operator to charge its battery as well as meet its load demand. The prosumers load can consist of a washing machine (WM), electric heater, etc as shown in Fig. 1. The day ahead hourly load profile of each prosumer is shown in fig. 2 as follows.

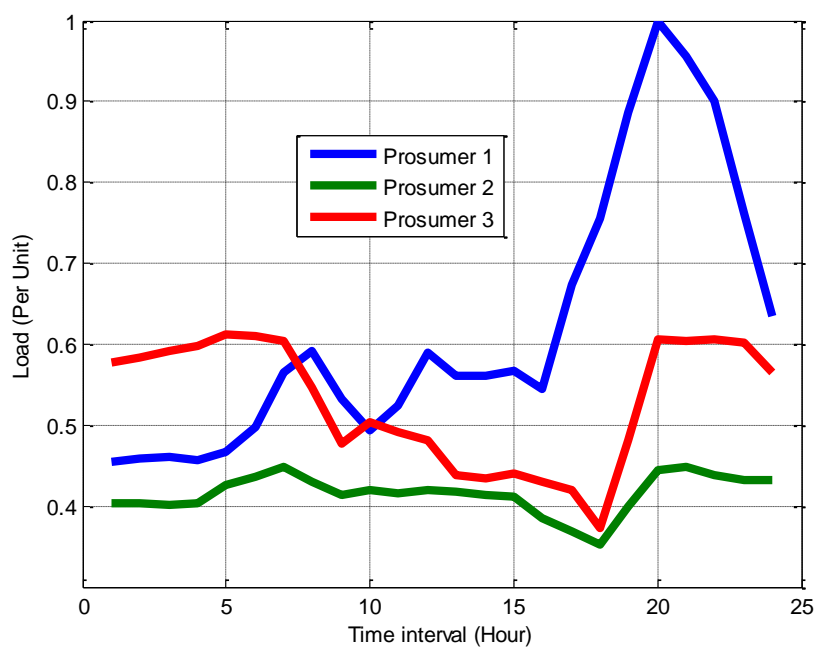

Fig. 2. Forecasted hourly load profile of each prosumer.

The hourly load data was obtained from Xcel Energy [20]. In Fig. 3, each of the prosumer has a different hourly load profile. The motivation of the prosumer as a participant in its local community VPP is to get incentive.

The VPP operator can buy energy from the grid and from the prosumers. The energy bought from the grid is use to meet the prosumer's energy demand respectively. The VPP buys power in bulk from the power market to meet its prosumer's load demand, as well as for charging the prosumers. In this model, the VPP can combine both energies from the grid and the prosumer's battery to meet the load demand of each prosumer respectively. The energy bought from each prosumer's battery are aggregated by the VPP. The aggregated energy is first use within the community to meet each prosumer's load demand respectively before it can be traded in the power market (exported to the external grid) by the VPP on behalf of the prosumers.

In this work, the VPP operator was considered as having a day ahead forecast of each prosumer hourly load profile respectively. In addition, the VPP operator has a day ahead forecast of the price at which the external grid would buy its energy (i.e. the day ahead forecast price paid by the grid to the VPP for exporting energy), as well as the day ahead forecast of the price at which the grid would sell energy (i.e. the day ahead forecast price paid by VPP to the external grid for importing energy). Both import and export prices for energy are agreed between the VPP operator and the grid in the wholesale power market. Based on the day ahead import and export price, the VPP operator agrees a day ahead prosumer buy and sell price of energy. Thereafter, the VPP operator has to optimally allocate energy resource by determining the day ahead schedule assuming no error band during forecasting. The day ahead energy resource allocation is done by determining the day ahead charge/discharge energy from each prosumer battery. The charge/discharge energy is use to control the amount of energy to be imported from grid and exported to the grid, and also to provide the balancing services required by the ISO (independent system operator). The financial reward for encouraging the VPP operator is profit.

\subsection{Electric Vehicle Scenario}

In this model, the prosumer uses its EV for participation in the power market. The difference between this model and that of the EES is that the battery is sometimes mobile. EV can only be use for market participation when it is idle. Fig. 3, is the diagram showing the VPP model under EV. 


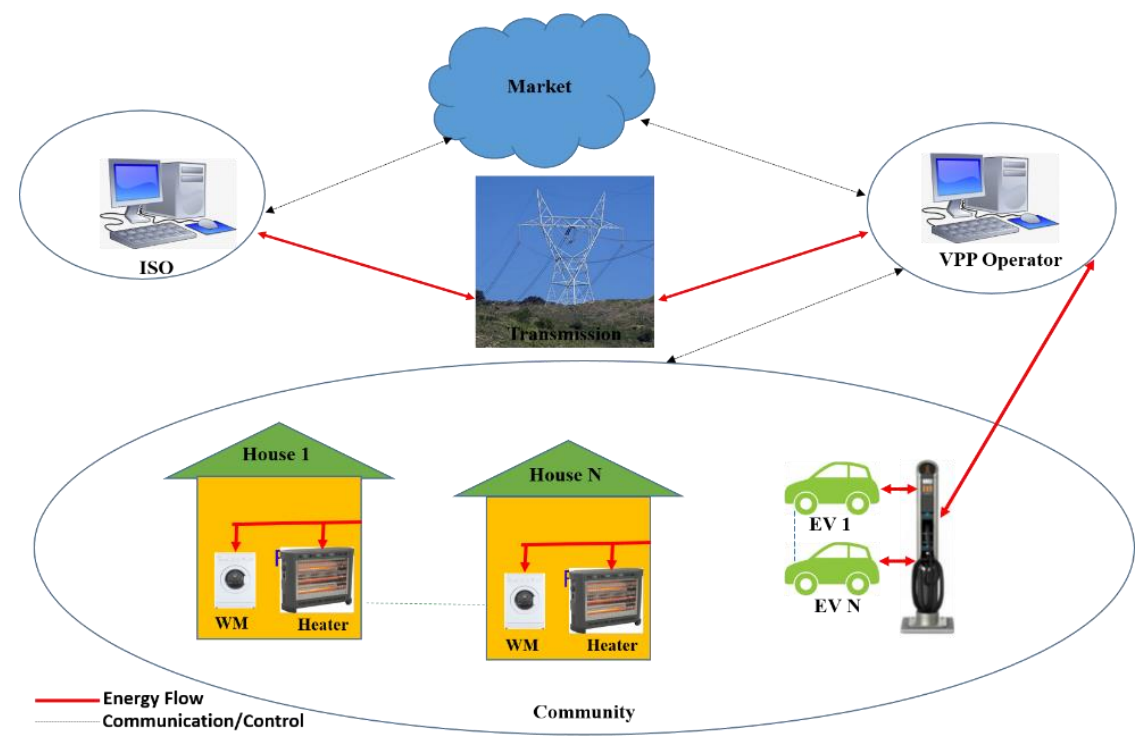

Fig. 3. Architecture of the Virtual Power Plant model (using EV).

In Fig. 3, each EV is labelled in accordance to the house number. Each house is own by a prosumer. The VPP combines in cloud each prosumer EV. The EV battery storage is regarded as virtual storage. This is because even though the vehicle is elsewhere within the community, it is still virtually connected to the VPP and the prosumer's house through smart plug and communication network. This allows the VPP to have information regarding the energy use by the EV for driving, as well as the energy traded and exchange between the VPP operator and prosumer's EV. The VPP uses the EV to participate in the wholesale power market only at time period when the prosumers plugged in their EV via the EVSE (Electric Vehicle Supply Equipment). The plugging operation can be done at the home and work location of the prosumer. The prosumer's home and work location are within the same community controlled by the VPP. During time period when the prosumers are driving their cars within their community (i.e. from home to work location, and from work location back to home) they are still virtually connected to the VPP, however during that time period the VPP cannot make use of the prosumers battery for energy transaction. At that time period the VPP can only transact energy based on the house load (domestic load) of the prosumer. Each prosumer house load pattern are the same as that of the EES scenario in fig. 2. The driving load profile of the prosumer is shown in fig. 4 , as follows.

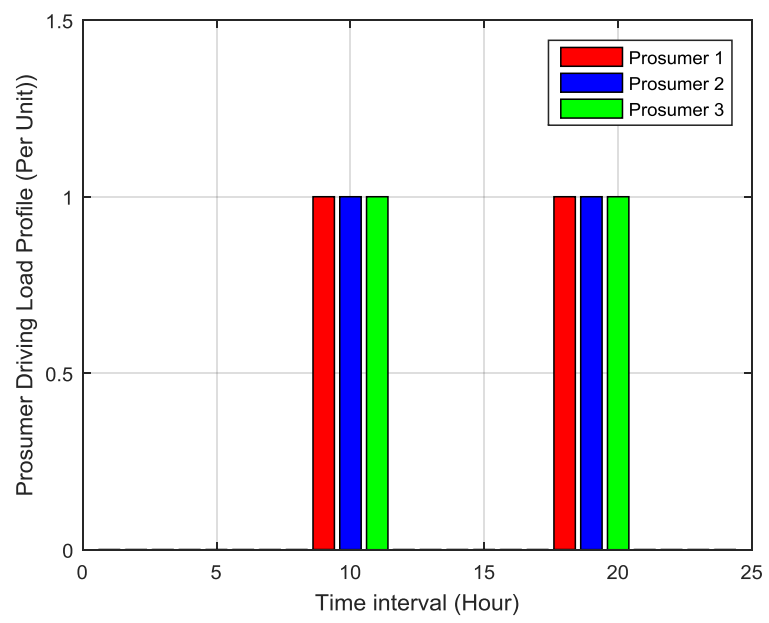

Fig. 4. Forecasted hourly driving load profile of each prosumer.

Fig. 4, is the driving load profile of each prosumer. It shows the energy consumed (discharged) from each prosumers EV during time period when the EV is been driven to work and back home. Each prosumer where assumed to have different driving pattern. In this work, it was considered that each prosumer EV is not available for VPP operation in terms of energy and business transaction for approximately $8 \%$ of the day total number of time interval (24 time interval). 


\section{Mathematical Tool used in Modelling}

\subsection{The VPP Net Dynamic Load}

The VPP net dynamic load at time interval $t$ on the grid is calculated in (1) as follows.

$$
\begin{gathered}
E_{g_{t}}=\sum_{i=1}^{N}\left(L_{i, t}+\alpha_{i, t} . E c d_{i, t}\right) \\
E c d_{i, t}=\left\{\begin{array}{l}
E_{c_{i, t}}, \text { if charg ing occur } \\
-E_{d_{i, t}}, \text { if disch } \arg \text { ing occur } \\
0, \text { if battery is idle }
\end{array}\right. \\
\alpha_{i, t}=\left\{\begin{array}{l}
1, \text { for VPP with } E E S \\
{[0,1], \text { for VPP with } E V}
\end{array}\right.
\end{gathered}
$$

Where $N$ is the total number of prosumers. $\alpha_{\mathrm{i}_{\mathrm{s}} \mathrm{t}}$ is the connection state of the prosumer's storage, which is either 0 or 1 . For VPP with EES, $\alpha_{i, t}$ is always 1 , this is because EES is stationary and always connected to the grid. For VPP with EV, $\alpha_{i_{j} t}$ is 1 when EV is plugged in (idle) at $t$, and 0 when EV is mobile at $t . E_{i m p}$ and $E_{\exp _{i, t}}$ are the amount of import and export energy in per unit respectively. $E c d_{i_{n}, t}$ is the amount of energy exchange in per unit between prosumer $i$ battery and the VPP at time interval $t . E_{c_{i, t}}$ and $E_{d_{i, t}}$ are the amount of charge and discharge energy in per unit respectively allocated to prosumer $i$ battery. $L_{i, t}$ is the load of prosumer $i$ in per unit at $t$. If $E_{g_{t}}$ is greater than zero, the VPP is importing energy, and if less it is exporting energy.

\subsection{VPP Operator Profit}

The VPP operator profit $V p p_{\text {profit }}$, at each time interval $t$ over the day's total number of time interval $(T)$ is calculated as follows.

$$
\sum_{t=1}^{T} V p p_{\text {profit }_{t}}=\sum_{t=1}^{T}\left(V p p_{\text {rev }_{t}}-V p p_{\cos t_{t}}\right)
$$

Where $V p p_{\text {rev }_{t}}$ and $V p p_{\cos _{t}}$ are the VPP revenue and cost respectively during the time interval $t$. $T$ is the day's total number of time interval. Both VPP revenue and cost are calculated in (3) and (4) as follows.

$$
\begin{gathered}
\sum_{t=1}^{T} V p p_{\text {rev }_{t}}=\sum_{i=1}^{N} \sum_{t=1}^{T}\left(\begin{array}{l}
P p_{\text {buyt }} \cdot\left(L_{i, t}+\alpha_{i, t} \cdot E_{c_{i, t}}\right) \\
+P v_{\exp _{t}} \cdot E_{\exp _{i, t}}
\end{array}\right) \\
\sum_{t=1}^{T} V p p_{\cos t_{t}}=\sum_{i=1}^{N} \sum_{t=1}^{T}\left(P p_{\text {sell }} \cdot \alpha_{i, t} E_{d_{i, t}}+P v_{\text {imp }_{t}} \cdot E_{\text {imp }_{t}}\right)
\end{gathered}
$$

Where $P p_{s e l l_{t}}, P p_{b u y_{t}}, P v_{i m p_{t}}$, and $P v_{e x p_{t}}$ are the prosumer selling price of energy to the VPP, prosumer buy price of energy from the VPP, the VPP import price of energy, and the VPP export price of energy respectively at $t$. These prices are measured in pence/per unit. $\alpha_{\mathrm{i}_{\mathrm{s}} \mathrm{t}}$ is the connection state of the storage, and is already explained in detail in section 3.1.

\subsection{Prosumer Net Cost}

The prosumer's net cost $P p_{\text {cost }}$, at each time interval $t$ over the day's total number of time interval $T$ is calculated as follows: 


$$
\sum_{t=1}^{T} P p_{\cos t_{t}}=\sum_{i=1}^{N} \sum_{t=1}^{T}\left(\begin{array}{l}
P p_{b u y_{t}} \cdot\left(L_{i, t}+\alpha_{i, t} \cdot E_{c_{i, t}}\right) \\
-P p_{\text {sellt }} \cdot \alpha_{i, t} \cdot E_{d_{i, t}}
\end{array}\right)
$$

\subsection{Battery State of Charge.}

The battery state of charge (SOC) gives an information on the battery energy level. In this work, the battery energy level is measured in per unit. Usually the battery SOC cannot be measured directly, but can be inferred from the battery energy level. Therefore, the battery state of charge of charge is a measure of the battery energy level in comparison to the battery actual capacity, assuming an ideal battery with no peukert effect, no losses (self-discharge) and whose actual capacity is the same as its nominal capacity. The SOC is measured in percentage. It gives an information on the battery depth of discharge. The battery energy level measured during $t$ is calculated as follows.

$$
E_{\text {stored }_{i, t}}=E_{o_{i}}+\sum_{t=1}^{T} E_{c d}
$$

$E_{\text {stored }_{i, t}}$ is prosumer $i$ battery energy level in per unit measured at $t . E_{o_{i}}$ is prosumer $i$ initial battery energy level in per unit before participation in the day ahead power market. Each prosumer battery SOC at $t$ is calculated as follows.

$$
\operatorname{SOC}_{i, t}=100 \frac{E_{\text {stored }_{i, t}}}{E_{\text {batt }_{i}}}
$$

$S O C_{i, t}$ is the state of charge of prosumer $i$ battery measured in percentage at $t . E_{b a t t_{i}}$, is the actual battery capacity in per unit of prosumer $i$.

\subsection{Battery Constraints}

Each prosumer battery discharge constraint is represented as follows.

$$
E_{d, \min _{i}} \leq E_{d_{i, t}} \leq E_{d, \max _{i}}
$$

Where $E_{d, \min _{i}}$ and $E_{d, \max _{i}}$ are the minimum and maximum discharge energy that can be allocated to prosumer $i$ battery. Each prosumer battery charge constraint is represented as follows.

$$
E_{c, \min _{i}} \leq E_{c_{i, t}} \leq E_{c, \max _{i}}
$$

Where $E_{c, \min _{i}}$ and $E_{c, \max _{i}}$ are the minimum and maximum charge energy that can be allocated to prosumer $i$ battery. Each prosumer battery state of charge constraint is represented as follows.

$$
S O C_{\min _{i}} \leq S O C_{i, t} \leq S O C_{\max _{i}}
$$

Where $S O C_{\min _{i}}$ and $S O C_{\max _{i}}$ are the minimum and maximum SOC limit of prosumer $i$ battery.

\section{Optimizations of the Community Virtual Power Plant}

To understand the optimization problem, the number of prosumer chosen to participate in the community VPP was kept at three. The optimization function is the prosumer net cost. This is gotten from (5) and is represented as follows.

$$
[\text { Min }] F=\sum_{t=1}^{T} P p_{\cos t_{t}}
$$

$F$ is the objective function to be minimize. It represents both the prosumer net cost. Genetic algorithm was used to solve the optimization problem [12], [13]. 


\section{Cumulative Performance Index for Measuring VPP Technical Performance}

The grid requires energy balancing service from the VPP. Energy balancing service is provided for by the VPP through peak and off-peak service. During off-peak period, the grid requires the VPP to increase its load, by importing energy from the grid to meet its prosumers load as well charging of battery. During peak period, the grid requires support from the VPP. The VPP can support the grid by discharging of its prosumer battery to meet the prosumers load demand, and also by exporting energy to the grid. The grid energy balancing need are reflected by the prices. More clarity on this is presented in section $\mathrm{V}$.

The VPP performance is determined by comparing both the VPP dynamic load and the energy balancing need of the grid.

The VPP dynamic load at $t, E_{g_{t}}$ is the energy imported from the grid by the VPP or the energy exported to the grid by the VPP at $t$. The energy balancing need of the grid at $t$ is determined by the exchange price $\left(\delta_{t}\right)$ at time $t$. This is calculated as the difference between the import and export price of electricity at $t$. This is mathematically represented as follows:

$$
\begin{gathered}
\delta_{t}=P_{\text {imp }}-P_{\exp _{t}} \\
\left\{\begin{array}{l}
\text { if } \delta_{t}>0, \text { grid requires off }- \text { peak service } \\
\text { if } \delta_{t}<0, \text { grid requires peak service }
\end{array}\right.
\end{gathered}
$$

When $\delta_{t}$ is positive, the grid requires the VPP to provide off-peak service by increasing its load. The VPP can increase its load by importing energy from the grid. When $\delta_{t}$ is negative the grid requires the VPP to reduce its load. The VPP can reduce its load by discharging the prosumer's battery to support the load, as well as to export energy to the grid. In this work, when energy is imported at $t, E_{g_{t}}$ (from (1)) is greater than zero. When energy is exported at $t, E_{g_{t}}$ is less than zero. Both $\delta_{t}$ and $E_{g_{t}}$ are represented with the logic input $A_{t}$ and $B_{t}$ respectively, such that:

$$
\left\{\begin{array}{l}
\text { if } \delta_{t}>0, \quad A_{t}=1 \\
\text { if } \delta_{t}<0, A_{t}=0 \\
\text { if } E_{g_{t}}>0, B_{t}=1 \\
\text { if } E_{g_{t}}<0, B_{t}=0
\end{array}\right.
$$

If grid requires off-peak service, it means the dynamic load must be increased. On the other hand, if the grid requires peak service, the dynamic load must be decreased. Based on this criteria, a performance state $C_{t}$ at time $t$ is derived as follows:

$$
C_{t}=\overline{\left(A_{t} \oplus B_{t}\right)}
$$

\section{Simulation Parameters}

TABLE. I. Parameters Used In Simulation.

\begin{tabular}{|l|l|}
\hline Parameters & Specification \\
\hline Ebatt & 24 per unit \\
\hline$E_{0}$ & 12 per unit \\
\hline Initial $S O C$ & $50 \%$ \\
\hline$E_{d_{d, \min }}$ & 0 per unit \\
\hline$E_{d_{d} \max }$ & 1 per unit \\
\hline$E_{c_{\text {man }} \min }$ & 0 \\
\hline$E_{c_{2} \max }$ & 1 \\
\hline$T$ & 24 \\
\hline$N$ & 3 \\
\hline
\end{tabular}




\section{Results and Discussion}

Fig. 5, is the modified pricing used in this model. This pricing scheme allows both the VPP and the prosumer to get business incentives.

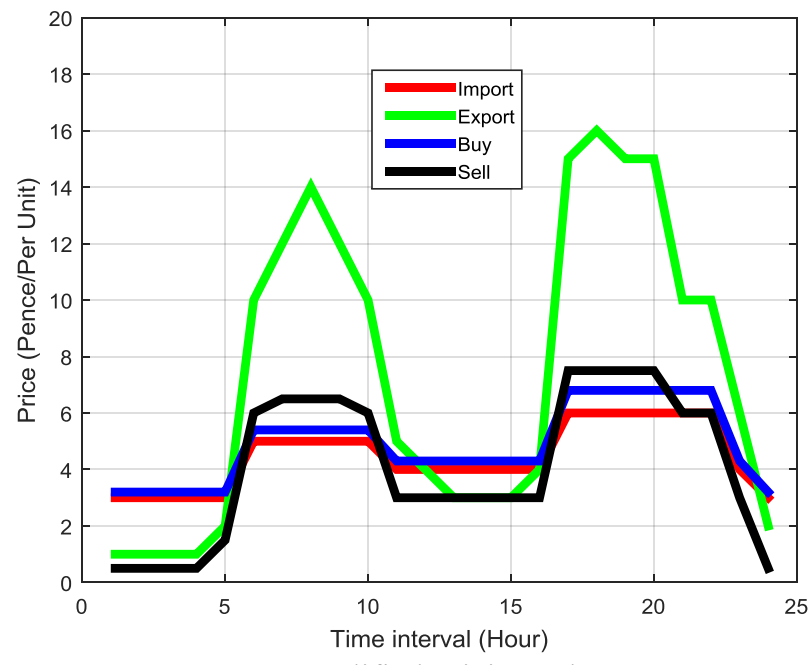

Fig. 5. Modified pricing scheme.

In Fig. 5, it is seen that the prices are set based on the grid requirement for dynamic load levelling. This pricing is detailed in [12], [13]. GA was used to optimized the energy transaction of the community. Fig. 6, is the cumulative prosumers incentive in both VPP with EES and VPP with EV scenario.

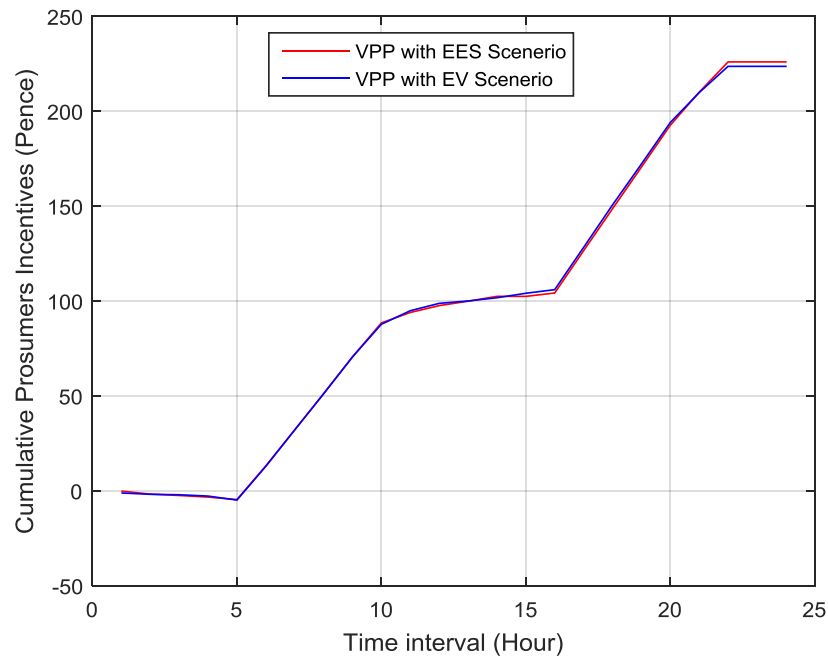

Fig. 6. Cumulative prosumers business incentives.

In Fig .6, it is seen that the prosumers get incentive under both scenario. In the VPP with EES scenario, the cumulative prosumers incentive was approximately 226 pence. In the VPP with EV scenario, the cumulative prosumers incentive was approximately 224 pence. The prosumers incentive is slightly higher for the VPP with EES scenario scenario as compared to the VPP with EV scenario. The higher incentive for VPP with EES is because the battery storage is $100 \%$ available (connected to the grid) for the prosumer to use for energy and business transaction with VPP. Using the percentage difference, the difference in prosumers incentives between VPP with EES and VPP with EV is very low. It is approximately $0.89 \%$. This is attributed to both the objective function and the pricing regime which favors the prosumers in both scenario. Fig. 7, is the cumulative VPP profit for both VPP with EES and VPP with EV scenario. 


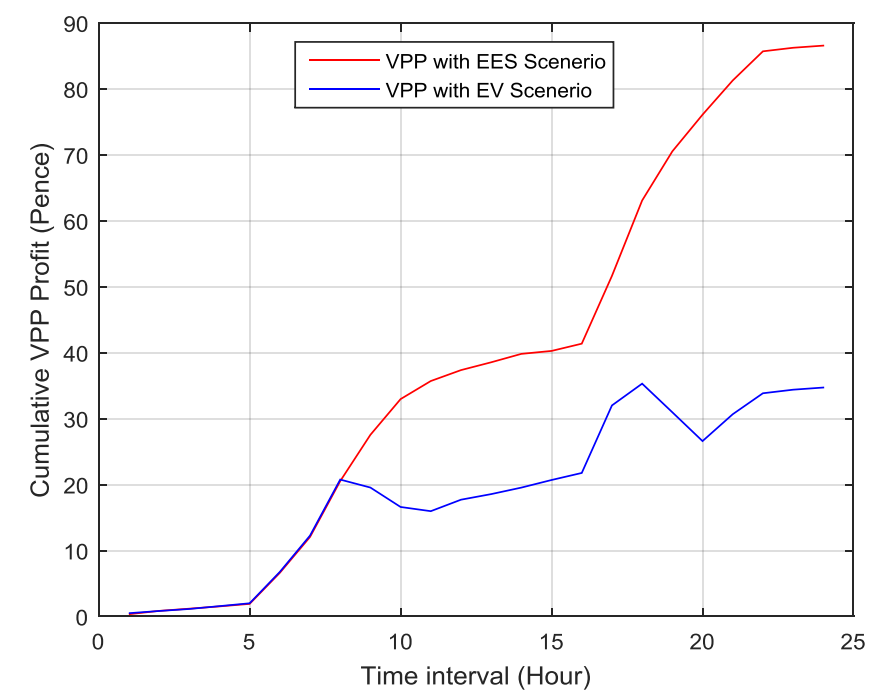

Fig. 7. Cumulative VPP business incentives

In Fig .7, it is seen that the VPP makes profit on both scenario. In the VPP with EES scenario the VPP makes a profit of approximately 87 pence. In the VPP with EV scenario the VPP makes a profit of approximately 35 pence, which is about $40 \%$ of what it makes in the EES scenario. The VPP operator profit under the EES scenario is much higher compared to that of the EV scenario. The percentage difference in VPP operator profit between VPP with EES and VPP with EV is approximately 85.3\%. This is unlike the prosumers incentives where the difference is low (apprimatelely $0.89 \%$ ). This high difference in VPP profit is due to VPP inability to fully utilize the prosumers battery for market participation during time periods when the EV owners is mobile; the battery discharge energy use for mobile activities; and the optimization function which favor's the prosumers incentive.

Fig. 8, is the cumulative performance of the under both VPP with EES and VPP with EV scenario.

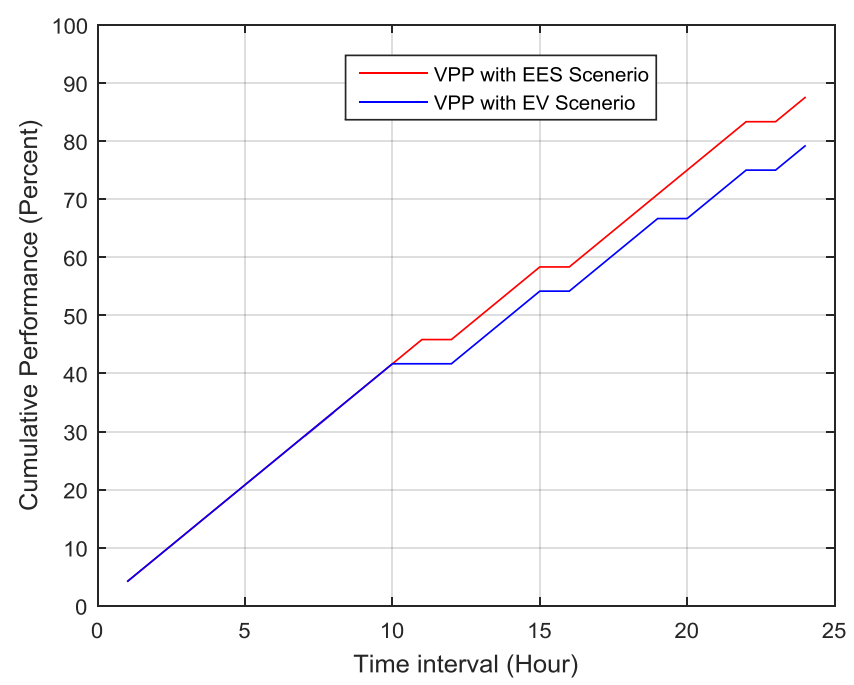

Fig. 8. Cumulative performance of the VPP.

In Fig. 8, it was observed that the VPP performance under the VPP with EES scenario is approximately $88 \%$. The VPP performance under the VPP with EV scenario is approximately $79 \%$. The percentage difference in the VPP cumulative performance between VPP with EES and VPP with EV is approximately 10.9\%. The VPP performs better with EES compared to EV because in the EES case scenario, the battery is always available to the VPP, and can be use by it for dynamic load levelling. Unlike the EV scenario, each of the prosumer's EV is only connected to the grid via the VPP for only $92 \%$ of the day total number of time interval ( 22 hours out of 24 hours). The remaining time period when the EV is not connected to the grid actually prevents the VPP from being able to provide dynamic load levelling. Thus resulting to a lower performance for the VPP.

In this work, the use of energy storage at the domestic level as part of a community VPP has been compared under two scenarios, which are the EES scenarios and the EV scenarios. Using percentage difference to compare both scenarios, the results clearly demonstrates that the best business case for prosumers may not necessarily mean the best business case for VPP operator. This is because even though the prosumers where allowed to use 
their battery energy to meet their driving need in the EV scenario, the percentage difference in their incentive as compared to the EES scenario is very low. This is unlike the VPP operator where the percentage difference is much higher between VPP with EES and VPP with EV (VPP operator profit too low for VPP with EV in comparison to VPP with EES). The same also applies to the best technical case for grid operators in terms of their requirement for dynamic load levelling. These factors should be considered by electric utilities and grid operators when selecting suitable business model and method of storage integration for VPP at the domestic level. For clarity purpose, Table II, is presented as follows.

TABLE. II. Comparison between VPP with EES and VPP with EV.

\begin{tabular}{|l|l|l|c|}
\hline & $\begin{array}{l}\text { VPP Operator } \\
\text { Profit }\end{array}$ & $\begin{array}{l}\text { Prosumers } \\
\text { Incentive }\end{array}$ & $\begin{array}{l}\text { Cumulative } \\
\text { Performance }\end{array}$ \\
\hline EES & 87 pence & 226 pence & $88 \%$ \\
\hline EV & 35 pence & 224 pence & $79 \%$ \\
\hline Percentage Difference & $85.3 \%$ & $0.89 \%$ & $10.9 \%$ \\
\hline
\end{tabular}

\section{Conclusion}

In this study, we have compared a community VPP with EES and a community VPP with EV in terms of business incentive and technical performance. Using the percentage difference, the results showed that the difference in prosumers incentives between VPP with EES and VPP with EV is very low. It is approximately $0.89 \%$. This is attributed to both the objective function and the pricing regime which favors the prosumers. While, past research works has demonstrated that most private cars are mobile for approximately $4 \%$ of the day total number of time interval and are idle for $94 \%$, we have considered EVs which are mobile for $8 \%$ of the day's total number of time interval in this work. Using the percentage difference, it is easy to understand that at $4 \%$ total number of time interval when EVs are mobile and disconnected from the grid, it is possible to have a minimal negative impact on the prosumers incentive if the prices are set correctly and the objective function is made to favor the prosumer. However, the percentage difference in VPP operator profit between VPP with EES and VPP with EV is very high. It is approximately $85.3 \%$. The same also applies to the VPP cumulative performance where the percentage difference in the VPP cumulative performance between VPP with EES and VPP with EV is approximately $10.9 \%$. Furthermore, there is a current demand towards a paradigm shift from fossil fuel vehicles towards EVs, therefore, it becomes critical to understand that having the best business case for prosumers may not necessarily mean the best business case for VPP operator. The same also applies to the best technical case for the grid operator in terms of its requirements for dynamic load levelling. Using percentage difference in Comparing VPP with EES and VPP with EV helps understand this. Future work would investigate different initial battery conditions and pricing models.

\section{Reference}

[1] H. Chen, T. N. Cong, W. Yang, C. Tan, Y. Li, and Y. Ding, "Progress in electrical energy storage system: A critical review," Progress in Natural Science, vol. 19, pp. 291-312, 2009.

[2] H. L. Ferreira, R. Garde, G. Fulli, W. Kling, and J. P. Lopes, "Characterisation of electrical energy storage technologies," Energy, vol. 53, pp. 288-298, 2013.

[3] Abbas A. Akhil, Georgianne Huff, Aileen B. Currier, Benjamin C. Kaun, Dan M. Rastler, Stella Bingqing Chen, et al., "DOE/EPRI 2013 Electricity Storage Handbook in Collaboration with NRECA," Sandia National Laboratories, Albuquerque, New Mexico SAND2013-5131, 2013.

[4] T. M. Masaud, K. Lee, and P. Sen, "An overview of energy storage technologies in electric power systems: What is the future?," in North American Power Symposium (NAPS), 2010, 2010, pp. 1-6.

[5] V. A. Boicea, "Energy Storage Technologies: The Past and the Present," Proceedings of the IEEE, vol. 102, pp. 1777-1794, 2014.

[6] P. Medina, A. Bizuayehu, J. P. Catalão, E. Rodrigues, and J. Contreras, "Electrical Energy Storage Systems: Technologies' Stateof-the-Art, Techno-economic Benefits and Applications Analysis," in System Sciences (HICSS), 2014 47th Hawaii International Conference on, 2014, pp. 2295-2304.

[7] IEA, "Technology roadmap: energy storage," Paris2014.

[8] W. Kempton, J. Tomic, S. Letendre, A. Brooks, and T. Lipman, "Vehicle-to-grid power: battery, hybrid, and fuel cell vehicles as resources for distributed electric power in California," Institute of Transportation Studies, 2001.

[9] W. Kempton and S. E. Letendre, "Electric vehicles as a new power source for electric utilities," Transportation Research Part D: Transport and Environment, vol. 2, pp. 157-175, 1997.

[10] W. Kempton and J. Tomić, "Vehicle-to-grid power fundamentals: calculating capacity and net revenue," Journal of Power Sources, vol. 144, pp. 268-279, 2005. 
[11] T. Fei and G. Strbac, "Business cases for energy storage with multiple service provision," Journal of Modern Power Systems and Clean Energy, vol. 4, pp. 615-625, 2016.

[12] O. Okpako, H.-S. Rajamani, P. Pillai, U. Anuebunwa, and K. S. Swarup, "Investigation of an optimized energy resource allocation algorithm for a community based virtual power plant," in PowerAfrica, 2016 IEEE PES, 2016, pp. 153-157.

[13] O. Okpako, H.-S. Rajamani, P. Pillai, U. Anuebunwa, and K. S. Swarup, "Evaluation of community virtual power plant under various pricing schemes," in Smart Energy Grid Engineering (SEGE), 2016 IEEE, 2016, pp. 72-78.

[14] C. Guille and G. Gross, "A conceptual framework for the vehicle-to-grid (V2G) implementation," Energy policy, vol. 37, pp. 4379-4390, 2009.

[15] L. Jingshan, Z. Shiyu, and H. Yehui, "FEDERAL AND STATE INCENTIVES HEIGHTEN CONSUMER INTEREST IN ELECTRIC VEHICLES," in Advances in Battery Manufacturing, Service, and Management Systems, ed: Wiley-IEEE Press, 2017, p. 416.

[16] J. A. P. Lopes, F. J. Soares, and P. M. R. Almeida, "Integration of electric vehicles in the electric power system," Proceedings of the IEEE, vol. 99, pp. 168-183, 2011.

[17] J. Iria, F. Soares, I. Franchin, and N. Silva, "Development of a novel management system for Electric Vehicle charging," in Electric Vehicle Conference (IEVC), 2014 IEEE International, 2014, pp. 1-7.

[18] G. T. Heydt, "The impact of electric vehicle deployment on load management straregies," Power Apparatus and Systems, IEEE Transactions on, pp. 1253-1259, 1983.

[19] D. Wu, D. C. Aliprantis, and L. Ying, "Load scheduling and dispatch for aggregators of plug-in electric vehicles," Smart Grid, IEEE Transactions on, vol. 3, pp. 368-376, 2012.

[20] X. Energy. (2012, 04/11/2016). Hourly Load Profiles. Available: https://www.xcelenergy.com/staticfiles/xe/.../AppendixDHourly_Load_Profiles.pdf 